NASA/TM-2003-212139

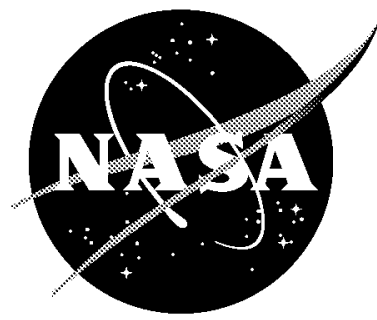

\title{
Development and Flight Testing of an Adaptable Vehicle Health-Monitoring Architecture
}

Stanley E. Woodard, Neil C. Coffey, Guillermo A. Gonzalez, Keith L. Woodman, Brenton W. Weathered, and Courtney H. Rollins

Langley Research Center, Hampton, Virginia

B. Douglas Taylor

Swales Corporation, Hampton, Virginia

Rube R. Brett

Zin Corporation, Hampton, Virginia 


\section{The NASA STI Program Office ... in Profile}

Since its founding, NASA has been dedicated to the advancement of aeronautics and space science. The NASA Scientific and Technical Information (STI) Program Office plays a key part in helping NASA maintain this important role.

The NASA STI Program Office is operated by Langley Research Center, the lead center for NASA's scientific and technical information. The NASA STI Program Office provides access to the NASA STI Database, the largest collection of aeronautical and space science STI in the world. The Program Office is also NASA's institutional mechanism for disseminating the results of its research and development activities. These results are published by NASA in the NASA STI Report Series, which includes the following report types:

- TECHNICAL PUBLICATION. Reports of completed research or a major significant phase of research that present the results of NASA programs and include extensive data or theoretical analysis. Includes compilations of significant scientific and technical data and information deemed to be of continuing reference value. NASA counterpart of peerreviewed formal professional papers, but having less stringent limitations on manuscript length and extent of graphic presentations.

- TECHNICAL MEMORANDUM. Scientific and technical findings that are preliminary or of specialized interest, e.g., quick release reports, working papers, and bibliographies that contain minimal amotation. Does not contain extensive analysis.

- CONTRACTOR REPORT. Scientific and technical findings by NASA-sponsored contractors and grantees.
- CONFERENCE PUBLICATION. Collected papers from scientific and technical conferences, symposia, seminars, or other meetings sponsored or co-sponsored by NASA.

- SPECTAl pUBLICATION. Scientific, technical, or historical information from NASA programs, projects, and missions, often concerned with subjects having substantial public interest.

- TECHNICAL TRANSLATION. Englishlanguage translations of foreign scientific and technical material pertinent to NASA's mission.

Specialized services that complement the STI Program Orfice's diverse offerings include creating custom thesauri, building customized databases, organizing and publishing research results ... even providing videos.

For more information about the NASA STI Program Office, see the following:

- Access the NASA STI Program Home Page at hrp://pww.sti.nasa.gov

- E-mail your question via the Internet to help@stinasa.gov

- Fax your question to the NASA STI Help Desk at $(301) 621-0134$

- Phone the NASA STI Help Desk at (301) 621-0390

- Write to:

NASA STI Help Desk

NASA Center for AeroSpace Information 7121 Standard Drive Hanover, MD 21076-1320 
NASA/TM-2003-212139

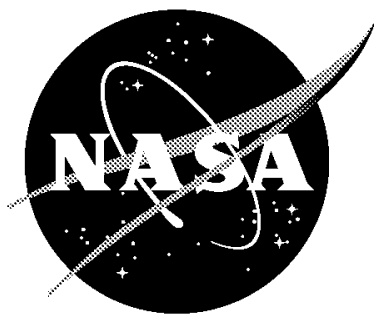

\section{Development and Flight Testing of an Adaptable Vehicle Health-Monitoring Architecture}

Stanley E. Woodard, Neil C. Coffey, Guillermo A. Gonzalez, Keith L. Woodman, Brenton W. Weathered, and Courtney H. Rollins

Langley Research Center, Hampton, Virginia

B. Douglas Taylor

Swales Corporation, Hampton, Virginia

Rube R. Brett

Zin Corporation, Hampton, Virginia

National Aeronautics and

Space Administration

Langley Research Center

Hampton, Virginia 23681-2199

January 2003 
Available from:

NASA Center for AeroSpace Information (CASI) 7121 Standard Drive

Hanover, MD 21076-1320

(301) $621-0390$
National Technical Information Service (NTIS) 5285 Port Royal Road

Springfield, VA 22161-2171

(703) 605-6000 


\begin{abstract}
Development and testing of an adaptable vehicle health-monitoring architecture is presented. The architecture is being developed for a fleet of vehicles. It has three operational levels: one or more remote data acquisition units located throughout the vehicle; a command and control unit located within the vehicle; and, a terminal collection unit to collect analysis results from all vehicles. Each level is capable of performing autonomous analysis with a trained expert system. The expert system is parameterized, which makes it adaptable to be trained to both a user's subject reasoning and existing quantitative analytic tools. Communication between all levels is done with wireless radio frequency interfaces. The remote data acquisition unit has an eight channel programmable digital interface that allows the user discretion for choosing type of sensors; number of sensors, sensor sampling rate and sampling duration for each sensor. The architecture provides framework for a tributary analysis. All measurements at the lowest operational level are reduced to provide analysis results necessary to gauge changes from established baselines. These are then collected at the next level to identify any global trends or common features from the prior level. This process is repeated until the results are reduced at the highest operational level. In the framework, only analysis results are forwarded to the next level to reduce telemetry congestion. The system's remote data acquisition hardware and non-analysis software have been flight tested on the NASA Langley B757's main landing gear. The flight tests were performed to validate the following: the wireless radio frequency communication capabilities of the system, the hardware design, command and control; software operation; and, data acquisition, storage and retrieval.
\end{abstract}




\section{CONTENTS}

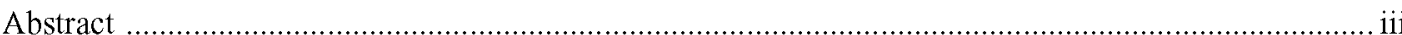

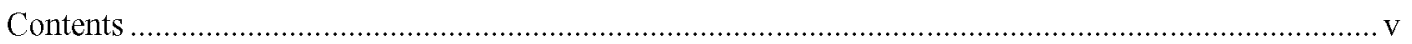

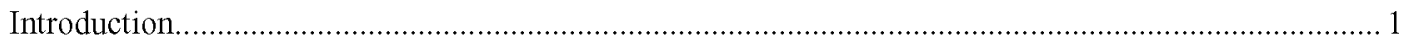

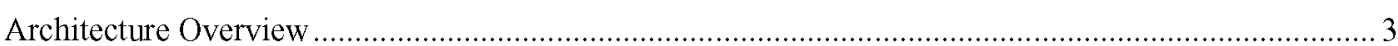

Remote Data Acquisition Unit (RDAU) .................................................................... 3

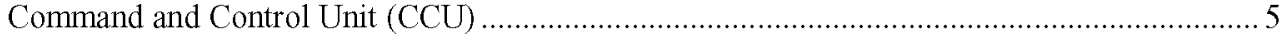

Terminal Collection Unit (TCU) …............................................................................ 5

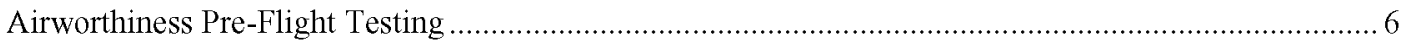

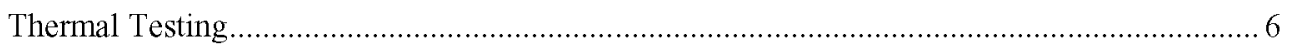

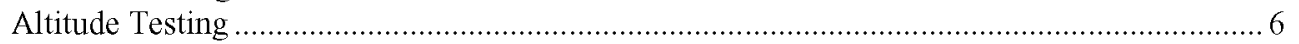

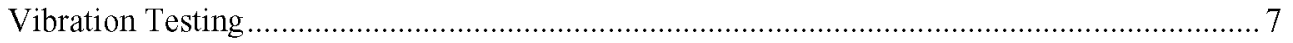

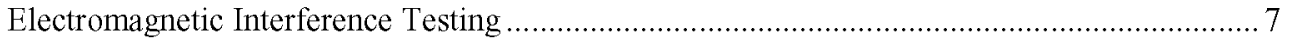

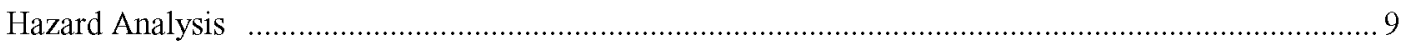

The Airborne Research Integrated Experiments System (ARIES) ................................................... 12

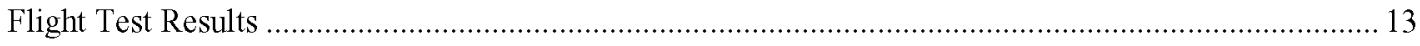

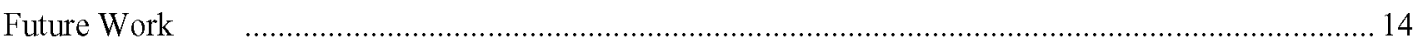

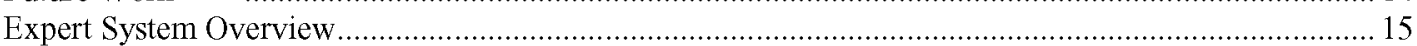

Conclusions

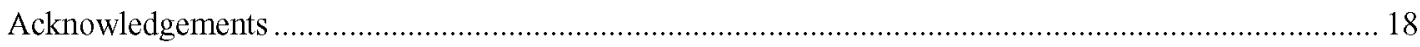

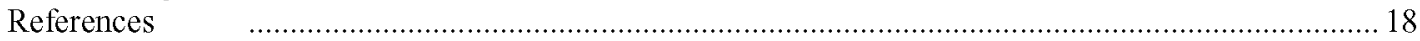

Figures 


\section{Introduction}

Existing aircraft are often kept in service beyond their original design lives. As they age, they become susceptible to system malfunctions or fatigue. Unlike future aircraft designs that will have health monitoring capabilities integrated into their designs, older aircraft have not been able to benefit from such technology. NASA Langley Research Center is developing and testing a health monitoring hardware/software architecture designed to be retrofitted into existing aircraft and thus provide them with state-of-the-art health monitoring capabilities. The objective of the health monitoring system is to reduce vehicle operating costs, improve safety and increase reliability. Frequent vehicle monitoring allows identification of the embryonic stages of damage or degradation. This knowledge can be used to correct the anomalies while still somewhat minor. In an "Aerospace America" commentary (January 2002), the former FAA Administrator and former Secretary of the Air Force, John McLucas, suggested the need for an aircraft health monitoring system. The system he described has all the attributes of the NASA health monitoring software and hardware architecture currently being developed and tested. The architecture provides a means to monitor vehicle and subsystem damage, degradation, usage and the manner in which vehicle subsystems are maintained.

The architecture is a hardware and software infrastructure for health monitoring that can be easily developed to a health monitoring system. The architecture presented herein is being developed for a fleet of vehicles. It has three operational levels: one or more remote data acquisition units (RDAU), a command and control unit (CCU), and a terminal collection unit (TCU). Programmable data acquisition circuitry and expert systems trained to performance baselines in each RDAU allow the architecture to be adaptable for many types of vehicles and structures. The programmable data acquisition circuitry allows type of sensor and number sensors used to be at the discretion of the user. The circuitry allows the sampling rate for each sensor to be programmed. Wireless radio frequency transceivers are used to communicate with all of the architecture components.

The architecture is capable of performing tributary analyses. The measurements collected at the lowest level are analyzed at that level. Analysis results are forwarded to a higher level and then all results are analyzed to ascertain global trends or anomalies for the prior level. This is repeated until all analyses are combined at the highest level. The architecture has three analysis levels. Each analysis level has a trained expert system. The lowest level consists of one or more remote data acquisition units (RDAU) capable of collecting and analyzing data. Each RDAU has multiple data acquisition channels. The RDAU can perform analysis on measurements from each channel individually or from all channels fused together. The second level is a command and control unit (CCU). The CCU is capable of performing vehicle level analysis. Each RDAU analysis results are forwarded to the CCU that can perform similar analysis but for all RADUs (i.e., the vehicle big picture). Global anomalies to the vehicle can be detected. The fused analysis can also be used to locate anomalies by triangulation. Spatial trends can also be identified using the fused analysis results. After the end-of-flight, a vehicle's CCU analysis is then forwarded to a terminal collection unit at the airfield. The terminal collection unit functions as a repository of all vehicle analyses and performs analyses using results forwarded from all vehicles. Here all vehicles can be compared to ascertain if there are common anomalies (e.g., vendor supplied bad brake pads, improperly manufactured linkage, etc).

Having expert systems at each analysis level can eliminate the need for transmitting and storing large volumes of collected measurements. An expert system develops analysis results that are transmitted to the higher system levels. The expert systems are developed such that they can be adapted to any system. The expert system's key analytic tool is fuzzy logic for inference logic based upon subjective reasoning and quantitative analysis. Fuzzy logic is used to emulate predicate reasoning (i.e., if " $\mathrm{A}$ " then "B") for many combinations of inputs which are used to form a decision. Fuzzy logic can also emulate human qualitative reasoning with the capability of incorporating multiple qualitative objectives. When pattern recognition is required, a neural network can augment the expert system. A neural network is a computational structure that emulates rudimentary biological neural processing. 
The health monitoring architecture provides a means for retrofitting a fleet of military and commercial aircraft, ships, and ground vehicles with state-of-the-art health monitoring technology. The architecture is self-contained and requires limited integration intrusion into existing systems. In essence, it has "bolton/bolt-off' simplicity that makes it easy to implement on any existing vehicle or structure. Because the architecture is completely independent of the vehicle, it can be certified for airworthiness as an independent system. The architecture provides a means to identify vehicle subsystem degradation or damage before they become costly and/or disastrous. Maintenance can be performed as needed instead of having the need for maintenance identified during cyclic inspections that take vehicles off duty even if there are no maintenance problems. Measurements and analyses acquired by the health monitoring architecture can be used to analyze mishaps. By identifying system problems before they become either costly or disastrous, vehicles can be more reliable and safer while increasing their duty time. Methods that increase safety by reducing risk reduce insurance costs.

The system's remote data acquisition hardware and non-analysis software has been flight tested on the NASA Langley B757's most severe location to mount a health monitoring device: the landing gear. Following the introduction will be an overview of the architecture hardware and software. Results from the airworthiness pre-flight tests (pressure, vibration, thermal and electromagnetic interference testing) will be presented next. Hazard analysis will follow. A brief overview of the NASA Langley Research Center (LaRC) Boeing 757-200 Airborne Research Integrated Experiments System (ARIES) is then given. Flight tests results are presented next. The next phase of the architecture development has already commenced and is described next. The next phase of development, that has already commenced. It includes installing autonomous capability for data reduction and analysis using the expert systems. Finally, in this next phase, the RDUA units will also be placed throughout the aircraft. 


\section{Architecture Overview}

The architecture is developed as a framework for tributary analysis for a fleet of vehicles. The three subsystems of the health monitoring architecture are the remote data acquisition unit, the command and control unit and the terminal collection unit. The details of each sub-system will be presented in this section.

\section{Remote Data Acquisition Unit (RDAU)}

Remote data acquisition units (RDAU) are multi-sensor interfaces with an on-board miniature computer, programmable digital interface, nonvolatile solid-state memory and a wireless transceiver for communication with the command and control unit. The RDAU electronics and housing are shown in Fig. 1. The software embedded in the RDAU computer provides transceiver control, encoder/decoder control, data file management. The autonomous analysis capability is currently being added to the architecture. The computer controls all functions for communication, data acquisition and storage. Sensor data is acquired via a flexible sampling scheme through a programmable digital interface. Currently a disk operating system (DOS) is being used which is to be replaced with a Linux operating system. A remote data acquisition unit can accommodate eight sensor measurements. Five AA Lithium batteries are used to supply power to each RDAU. External power sources can also be used. The housing and the mounting of internal electronics are designed to withstand impact during aircraft landing while mounted on the main landing gear. It is also designed to operate in non-environmentally controlled locations of the plane. The device can operate at $-50^{\circ} \mathrm{C}$ to $55^{\circ} \mathrm{C}$ and pressure equivalent to $50,000 \mathrm{ft}$ altitude.

Any combination or type of sensors can easily be installed into the RDAUs. These sensors can be within the RDAU housing or external to the RDAU (e.g., connected with wires or flex circuits). Data acquisition circuitry is implemented in a single complex programmable logic device (CPLD). A complex programmable logic device can be reconfigured in-circuit. A device performing a similar function is a field programmable gate array. The circuitry controls all analog-to-digital conversion. A first in/first out sample buffer and the buffer status is regulated by the circuitry. Time division multiplexed (TDM) sampling is used to provide multiple sampling rates for the individual channels within a prescribed sampling period. When sensors are measuring physical properties with different rates of change, the multiple sampling rates eliminates excessive sampling of a property that changes at a slower rate.

A transceiver operating at $433 \mathrm{MHz}$ was used for communication with the command and control unit. The transceiver used $1 \mathrm{~mW}$ of power. The transceiver used amplitude shift keying modulation (somewhat similar to amplitude modulation). The frequency does not electro-magnetically interfere with aircraft communication and navigation systems. A micro-controller regulates the transceiver power management logic. The transceiver power management algorithm regulates the RDAU transceiver to power-off for $2 \mathrm{~s}$, then power-on for $2 \mathrm{~ms}$ to acquire any commands broadcast from the command and control unit. It then returns to power-off for $2 \mathrm{~s}$ if no commands are broadcast. The algorithm continuously cycles the transceiver power in the aforementioned fashion. If there are broadcast commands, the transceiver remains on until the commands are completed. Each RDAU has an addressable encoder/decoder. Commands can be received directly through the encoder/decoder. RDAU status and data are received through serialized packet format.

Once a suite of sensors are chosen for each RDAU and located on the vehicle, a baseline of acceptable vehicle performance is established from measurements acquired when the vehicle is performing correctly. Each RDAU uses an embedded expert system trained to its respective baseline. The expert system will be discussed in a later section. Expert systems are currently being added to the RDAU processor to incorporate both subjective human reasoning and other analysis algorithms in all operational levels of autonomous analysis. Once trained, the expert system uses anomalies to the baseline patterns to identify possible changes to vehicle structure or subsystems. The expert systems provide a means to autonomously gage how significant measured changes to established baselines are. Transceivers are used to communicate 
between all system levels. Analysis results are transmitted to higher system levels in lieu of all collected data to eliminate telemetry congestion.

\begin{tabular}{|l|l|}
\hline Channel & Measurement \\
\hline 1 & $\begin{array}{l}\text { Acceleration in } \\
\text { velocity direction }\end{array}$ \\
\hline 2 & $\begin{array}{l}\text { Acceleration along } \\
\text { pitch axes }\end{array}$ \\
\hline 3 & $\begin{array}{l}\text { Acceleration in } \\
\text { vertical direction }\end{array}$ \\
\hline 4 & Sound \\
\hline 5 & RDAU Temp \\
\hline 6 & Battery Voltage \\
\hline 7 & Spare \\
\hline 8 & Reference \\
\hline
\end{tabular}

Table 1 Remote data acquisition channel allocation

Each RDAU can sense numerous physical attributes (e.g., sound, heat, or mechanical disturbance) within vicinity of a RDAU. Table 1 lists measurements of each channel during the flight tests. In nominal operation, each physical attribute sensed by a sensor interfaced to a RDAU has a performance envelope or established pattern that are indicative of the system (vehicle or plant) being and/or functioning within acceptable limits. Examples of these are measured landing gear loads during impact not being exceeded; brake noise frequency spectral content within established range, no major changes to structural frequencies that can be sense by a RDAU, or no anomalies in audio or vibration signatures. Basically, each RDAU has a collection of measurement signatures (i.e., profiles) established from measurement during correct and non-damaged operations of the system. Measured profiles that show alterations to the signatures infer the system has changed. 


\section{Command and Control Unit (CCU)}

The command and control unit is a computer-based subsystem that provides the communications, analysis repository, and user interface functions for RDAU control, data archiving, and analysis. The command and control unit is shown in Fig 2a. Fig $2 \mathrm{~b}$ shows the transceiver for the CCU. The CCU can also serve as a power management tool by regulating when individual or combinations of RDAUs are powered on. A simple radio frequency (RF) wireless network of RDAUs can be controlled from a single CCU. Communication, for RDAU control, is provided via a custom wireless RF transceiver interface. The CCU can be manually controlled and reconfigured via standard computer interfaces (e.g., standard serial cable to a portable PC such as a laptop, personal digital assistance; or, keypad). If the CCU must be embedded further into the vehicle/plant, control and configuration could be carried out remotely via a RF communication. A user interface is provided to allow the user to control functions for a selected RDAU. Data and/or analyses, downloaded from the associated acquisition units, are archived for the next level of analysis.

The CCU regulates the health monitoring architecture. It has a wireless transceiver to communicate with all RDAUs via two-way RF. The CCU controls all RDAUs with the following commands: power on-off, acquire, trigger, stop, reset, status and download. It has the ability, using expert systems, to reduce and analyze all data collected. The CCU can be controlled and reconfigured manually by use of any portable PC such as a laptop, personal digital assistant via a standard serial port. A keypad with LCD display is also part of the CCU. Currently a disk operating system (DOS) is being used which is to be replaced with a Linux operating system.

\section{Terminal Collection Unit (TCU)}

The terminal collection unit (TCU) provides the means to autonomously retrieve vehicle analysis results from all vehicle CCUs. The TCU performs analysis on all results collected from all vehicles to identify any fleet-wide anomalies (e.g., all aircraft have the same faulty bearing at a similar location). The TCU will be used to develop the final summary of the vehicle health monitoring results that gets routed to the appropriate users (e.g., maintenance workers, airlines operations, etc.). The TCU is currently under development. A portable system that contains the non-analysis capabilities of the TCU has been successfully demonstrated to download data after flights. The TCU is embodied as a Linux-based processor with RF communication, internet connectivity, expert systems and installed software similar to that to be installed on the CCU. The TCU will constantly transmit a "power on" command while awaiting the arrival of vehicles to within range of its transceiver. This command is repeated until there is a vehicle with $\mathrm{CCU}$ in vicinity. When a vehicle is in vicinity, its $\mathrm{CCU}$ will be powered on and then all collected analysis will be transmitted. All newly collected results are then compared to those of other vehicles that have been collected. Any fleet wide anomalies are then automatically reported to appropriate users via shell commands which query the appropriate directories for new analysis reports and then to forward reports via emails or file transfer protocols. 


\section{Airworthiness Pre-Flight Testing}

Pre-flight tests were performed to validate the airworthiness of the remote data acquisition unit. The tests were to verify the operation of all electrical components, software and radio frequency communication. The tests performed were thermal cycling, pressure, vibration and electromagnetic interference. The integrity of the mechanical design which included housing and mounting of electrical components was partially verified during vibration testing. The pre-flight airworthiness tests were performed in accordance to Ref 1 . The complete validation of the design was the objective of the flight tests.

\section{Thermal Testing}

The remote data acquisition unit was operated at various temperatures to verify its ability to function at those temperatures. The RDAU was placed in a Tenney Jr. Temperature Chamber for eight continuous hours. The chamber is shown in Fig 3. The temperature in the chamber was varied according to the temperature profile shown in Fig. 4. Fig 4 shows the profile used for the pre-flight qualification test and results of the qualifying test. Results of thermal testing prior to the qualifying test are also shown in Fig 4. During qualification, there were four periods at which the temperature was held constant. The temperature rate of change between the holding periods was approximately $2.5^{\circ} \mathrm{C}$ per minute. Temperature variation for flight qualification was from $20^{\circ} \mathrm{C}$ to $-40^{\circ} \mathrm{C}$ to $55^{\circ} \mathrm{C}$ to $20^{\circ} \mathrm{C}$. During preliminary testing the temperature varied from $20^{\circ} \mathrm{C}$ to $-50^{\circ} \mathrm{C}$ to $20^{\circ} \mathrm{C}$. The temperature was maintained at $-50^{\circ} \mathrm{C}$ for $5 \frac{1}{2}$ hours.

Operation verification points are annotated on Fig 4. At each measurement time, the RDAU was commanded by the CCU to POWER ON. The POWER ON command instructed the computer that controlled data acquisition to be turned on. The CCU then transmitted an ACQUIRE command which instructed the RDAU to acquire measurements for all eight channels. Following the ACQUIRE command, the CCU transmitted a DOWNLOAD command which instructed the RDAU to transmit data packets to the CCU while the CCU received and stored the packets. A POWER OFF command was then sent to the RDAU to place the RDAU in a sleep mode. In the sleep, mode the computer which is used to control data acquisition and data storage was powered off. The micro-controller that controls the transceivers initiates the power management algorithm. The data received and stored by the CCU was then examined. The data was manually examined to verify that the correct pre-selected count (for reference channel) and the correct number of bytes for other the channels was received. The time and temperature of the oven was recorded at different intervals. The RDAU functioned correctly at all measurement points for all tests.

\section{Altitude Testing}

To emulate pressure conditions at 50,000 ft, the RDAU was placed in a Process Equipment Co. vacuum chamber with the chamber pressure decreased to and stabilized at $87.0 \mathrm{~mm} \mathrm{Hg}$ (pressure at 50,000 $\mathrm{ft}$ for standard day). The chamber is shown in Fig 5. The test initiated with the chamber temperature at ambient temperature. The RDAU was positioned in the chamber so that it could be viewed through the front window of the chamber. Since the RDAU was battery operated with a radio frequency transceiver, no wiring connections were necessary. A radio frequency spectrum analyzer was used to verify that communications signals were either sent by the command and control unit or by the RDAU. During testing, the CCU was external to the vacuum chamber. The RDAU was tested prior to the altitude test to assure that it was working properly. Transceiver communication between the CCU and RDAU was verified before start of test with the pressure chamber door closed.

The chamber pressure was decreased to $87.0 \mathrm{~mm} \mathrm{Hg}$ and maintained at that pressure for two hours. The RDAU performance was monitored during the two hours by acquiring measurements from all channels every 30 minutes. No malfunctions were observed for either the CCU or the RDAU during the altitude 
test. The operation of the RDAU was again verified after the vacuum chamber pressure was increased to ambient and the chamber was opened.

\section{Vibration Testing}

To verify that the remote data acquisition unit could operate during vibration that was representative of what commercial transports could experience, the RDAU was subjected to a vibration test. A T1000 Unholtz-Dickie vibration table, shown in Fig. $6 \mathrm{a}$, was used to provide the desired acceleration. The RDAU was subjected to the two sinusoidal vibration spectrums shown in Figs. 7 and 8 for each orthogonal axes shown in Fig 6b. Both sine-sweep tests were conducted in each axis before changing to next axis orientation. During the standard sinusoidal test (Fig 7), the frequency of acceleration was increased from $10 \mathrm{~Hz}$ (at $0.511 \mathrm{~g}$ ) to $2000 \mathrm{~Hz}$ at a rate of 1 octave $/ \mathrm{min}$. The final acceleration amplitude was $20 \mathrm{~g}$. At 2000 $\mathrm{Hz}$, the sweeping frequency was decreased at $1 \mathrm{octave} / \mathrm{min}$ until the vibration table acceleration frequency reached $10 \mathrm{~Hz}$. Similarly, during the high level short duration sinusoidal test (Fig. 8), the acceleration frequency was increased from $10 \mathrm{~Hz}$ to $250 \mathrm{~Hz}$ at a rate of $0.166 \mathrm{~Hz} / \mathrm{s}$. The sweep was also reverse after reaching $250 \mathrm{~Hz}$. Two diagonally mounted accelerometers were mounted on the table for reference measurements. During testing, a spectrum analyzer was used to verify radio frequency transmissions from the RDAU. The command and control unit was placed in the vibration table control room.

Before testing each axis, the RDAU was turned POWERED ON to verify operation. Shortly after the sinusoidal sweep started, the RDAU was commanded to record 10 seconds of data. Audio and acceleration measurements acquired during the $\mathrm{Y}$-axis vibration tests are shown in Fig. 9 for $0.05 \mathrm{~s}$. The measurements were taken when the table was vibration at approximately $240 \mathrm{~Hz}$. After each sinusoidal sweep has ended, the RDAU was commanded to download the data to the CCU. The CCU file directory was examined to verify the download. After the download was verified, the RDAU was commanded to the sleep mode. No malfunctions were observed for either the CCU or the RDAU during all vibration sweeps.

\section{Electromagnetic Interference Testing}

Research experiments that fly on the NASA Langley Research Center (LaRC) Boeing 757-200 Airborne Research Integrated Experiments System (ARIES) must be tested to determine if they cause electromagnetic interference to communication receivers and/or navigation receivers on-board the aircraft. ${ }^{1,2}$ Aircraft-level testing was performed when there were major configuration changes on the 757 ARIES. Experimental equipment was normally required to be cleared for all phases of flight, including takeoff and landing. Any interference to the communication and navigation equipment is a potential safety risk. C. H. Rollins provides (Ref. 2) a very detailed description of the testing required for flight. Features of testing relevant to the health monitoring system are summarized in this section.

Table 2. Receiver Antenna Port Measurements

\begin{tabular}{|c|c|}
\hline Receiver Measured & Frequency Range (MHz) \\
\hline Marker Beacon & $74.8-75.2$ \\
\hline VOR & $108-118$ \\
\hline ILS Localizer & $108.1-112$ \\
\hline ILS Glideslope & $328-335$ \\
\hline UHF & $225-400$ \\
\hline VHF & $118-138$ \\
\hline DME & $960-1220$ \\
\hline
\end{tabular}

The aircraft-level testing determined the interference from the research equipment to the communication and/or navigation receivers. Interference to other systems was determined during Instrumentation Check 
Flights (ICFs). The aircraft-level testing provided the exact environment and RF coupling paths thereby producing more accurate results than could be achieved if the individual instruments were examined in electromagnetic interference laboratory. Because the radiated emissions profile for the research system was not known, the entire operational band was swept for each receiver.

Aircraft-level testing was performed after all research pallets passed flight quality assurance inspections. All research pallets were in flight configuration and were operating in a normal flight mode for this testing. The interference levels were measured at the antenna ports for each of the communication and navigation receivers and then the receivers were tuned to any suspect frequencies to determine if the level was sufficient to cause interference. The electromagnetic interference test measured the level of noise at the input to the receivers listed in Table 2. Operational frequencies for the receivers are also listed in Table 2.

During measurements, the applicable aircraft receiver's antenna was used as the measurement antenna. The signal received from the antenna is used as the input to a spectrum analyzer. Fig 10 shows the analyzer connected to an antenna via a coaxial cable. The measurement scan of the receiver band was first performed with all research equipment powered off. The applicable receiver frequency band was scanned using the spectrum analyzer. A minimum of three sweeps was made at each frequency band to determine the baseline response and to ascertain any significant noise present. The purpose of the baseline scan was to identify any noise that was not due to the research system. Next, the measurement scan was performed with all the research equipment powered on. Any noise signals measured are compared to those recorded in the baseline scan. If the signal was not previously identified, the frequency and level are recorded and the signal plotted. Next, the research pallets were powered down one at a time while displaying each identified signal. The source of the potential interference signal was identified when the signals were not present when the equipment was powered off. Once the research pallet was identified, individual equipment on the pallet was powered on and off to determine the source of the interference within the research equipment. This procedure was repeated for each receiver listed in Table 2.

After the potential interference was identified, a receiver check was performed. The receiver check determined which potential interference signals were of sufficient strength to cause interference to the communication receivers. These frequencies of interference and the source of interference were reported to the pilots so that they were aware of any unusable communication frequencies. It is difficult to determine interference to the navigation receivers during the receiver checks. Therefore, all frequencies of potential interference to the navigation receivers were reported to the pilots and the sources of the interference were noted so that the pilots were aware at what frequencies the receivers may experience interference.

By performing a functional check of critical and essential systems, the pilots determine any interference to other systems during the ICFs. The correct operation of the navigation receivers at the identified potential interference frequencies was also verified during the ICFs. A functional check of as many instrument operational modes as possible for the applicable phases of flight was performed.

The major source of electromagnetic emission from the health monitoring system was from the use of the radio frequency transceivers. The transceivers operated at $433 \mathrm{MHz}$ which was above the UHF band (225 - $400 \mathrm{MHz})$ and significantly below the DME band $(960-1220 \mathrm{MHz})$. The entire emission of the health monitoring system had no influence on the UHF antenna. No other systems had operational frequency bands for which the health monitoring system could possibly interfere. The transmission frequency and harmonics did not fall within any of the radio frequencies communication and navigation bands checked. 


\section{Hazard Analysis}

Potential hazards were identified and analyzed to assure safety during the test flights. The initial flight tests were performed with the remote data acquisition unit mounted on the tow fitting of the left main gear. Table 3 lists six potential hazards that were identified. The corrective and/or preventative actions are also included in the table immediately below the appropriate hazards. 


\begin{tabular}{|c|c|c|c|}
\hline Potential Hazard & Undesired Event & Cause of Potential Hazard & Effect Of Undesired Event \\
\hline $\begin{array}{l}\text { 1. Controlled flight into terrain/loss of } \\
\text { control/failure of landing gear to } \\
\text { extend/retract due to electrical failure }\end{array}$ & $\begin{array}{l}\text { Controlled flight into terrain/loss } \\
\text { of control/failure of landing gear } \\
\text { to extend/retract }\end{array}$ & $\begin{array}{l}\text { Electrical shorting due to design error, } \\
\text { installation error or water intrusion }\end{array}$ & Loss of aircraft or serious injury or death \\
\hline $\begin{array}{l}\text { 2. Controlled flight into terrain/loss of } \\
\text { control/failure of landing gear to } \\
\text { extend/retract due to mechanical failure }\end{array}$ & $\begin{array}{l}\text { Controlled flight into terrain/loss } \\
\text { of control/failure of landing of } \\
\text { landing gear to extend/retract }\end{array}$ & $\begin{array}{l}\text { Mechanical failure due to design error, } \\
\text { fracture failure (affecting tires, } \\
\text { brakes/anti-skid, flaps, etc.), or } \\
\text { mechanical interference with systems in } \\
\text { wheel well (i.e., electrical, hydraulic. } \\
\text { landing gear, brakes/anti-skid, etc.) }\end{array}$ & Loss of aircraft or serious injury or death \\
\hline $\begin{array}{l}\text { 3. Damage or injury due to unintended } \\
\text { release of stored energy in tires } \\
\text { (pneumatic) }\end{array}$ & $\begin{array}{l}\text { Damage or injury due to } \\
\text { unintended release of stored } \\
\text { energy in tires }\end{array}$ & $\begin{array}{l}\text { Tires mechanically damaged due to } \\
\text { failure of transmitter box or components }\end{array}$ & Tire damage, serious injury or death \\
\hline $\begin{array}{l}\text { 4. Foreign object hazard created on } \\
\text { runway due to mechanical failure of } \\
\text { transmitter unit }\end{array}$ & $\begin{array}{l}\text { Foreign object damage (FOD) } \\
\text { on runway }\end{array}$ & Mechanical failure of transmitter unit & Aircraft damage, serious injury \\
\hline \multicolumn{4}{|c|}{$\begin{array}{l}\text { Corrective/Preventative Action for Hazard 1-4: } \\
\text { Extensive airworthiness and safety reviews of the remote data acquisition unit design and the preflight testing was used to alleviate the potential hazards identified. } \\
\text { Installment of all health monitoring subsystems were given thorough flight quality assurance inspections. }\end{array}$} \\
\hline
\end{tabular}

Table 3 Potential hazards associated with remote data acquisition unit being mounted on main landing gear 


\begin{tabular}{|c|c|c|c|}
\hline Potential Hazard & Undesired Event & Cause of Potential Hazard & Effect Of Undesired Event \\
\hline $\begin{array}{l}\text { 5. Controlled flight into terrain/loss of } \\
\text { control due to electromagnetic } \\
\text { interference (EMI) }\end{array}$ & $\begin{array}{l}\text { Controlled flight into terrain/loss } \\
\text { of control/failure of landing of } \\
\text { landing gear to extend/retract }\end{array}$ & $\begin{array}{l}\text { Electromagnetic interference affects } \\
\text { ship's avionics and/or nearby ground } \\
\text { stations. }\end{array}$ & Loss of aircraft or serious injury or death \\
\hline \multicolumn{4}{|c|}{$\begin{array}{l}\text { Corrective/Preventative Action for Hazard 5: } \\
\text { 1. EMI testing was performed to measure interference with RDAU operating at } 433 \mathrm{MHz} \text { and } 1 \mathrm{~mW} \text {. } \\
\text { 2. Blackout zone was planned where transfer of data from RDAU(s) to CCU was not scheduled. This zone was initially defined as } 1,000 \mathrm{ft} \text { AGL. } \\
\text { 3. Tests and procedures were developed to ensure no impact on Instrument Landing Systems (ILS) when near ground or interference with B-757 avionies (e.g., no } \\
\text { active or passive transmission during critical flight maneuvers). } \\
\text { 4. No hardwired interface was allowed to B-757 aireraft systems }\end{array}$} \\
\hline $\begin{array}{l}\text { 6. Damage or injury due to unintended } \\
\text { release of stored electrical energy, } \\
\text { radiation, or electrocution }\end{array}$ & $\begin{array}{l}\text { Equipment damage or personnel } \\
\text { injury }\end{array}$ & $\begin{array}{l}\text { Batteries in transmitting unit explode due } \\
\text { to high temperatures or charging failure }\end{array}$ & System damage, personnel injury or death \\
\hline \multicolumn{4}{|c|}{$\begin{array}{l}\text { Corrective/Preventative Action for Hazard 6: } \\
\text { 1. Batteries were not chargeable and were replaced on condition. } \\
\text { 2. Voltage outputs were monitored from experimental pallet and were used to predict replacement requirements. } \\
\text { 3. Batteries are sealed within a metal enclosure, that has been analyzed/reviewed for structural integrity. } \\
\text { 4. Five AA lithium batteries were mounted inside each RDAU. } \\
\text { 5. Power output is } 1 \mathrm{~mW} \text {. } \\
\text { 6. Laptop batteries are considered to be in the normal flight use profile. }\end{array}$} \\
\hline
\end{tabular}

Table 3(Continued) Potential hazards associated with remote data acquisition unit being mounted on main landing gear. 


\section{The Airborne Research Integrated Experiments System (ARIES)}

The Airborne Research Integrated Experiments System is a Boeing 757-200 that has had its cockpit and fuselage reconfigured to serve as a platform for experimental aerospace and atmospheric science systems. ${ }^{3}$ The ARIES is shown in Fig. 11. A detailed description of ARIES is given in Ref 3. The aircraft was manufactured in1983 for Eastern Airlines. The ARIES can easily support multiple experiments concurrently. The aircraft characteristics are given in Table 4 . The baseline research configuration of the ARIES includes twelve instrumented test pallets/research stations. Additional pallets and research equipment can also be installed. The pallets are primarily located in the passenger cabin. Each pallet has dual video monitors and an UTC synchronized time display. Video cameras are located in the landing gear well pointing toward the gear; on the aircraft tail pointing forward; in the rear cockpit with view of cockpit; and, forward cockpit providing a nose view.

Other equipment is located throughout the aircraft, such as research displays mounted in the forward flight deck and a telemetry pallet located in the aft life raft overhead storage compartment. There are external video cameras and various special-purpose antennas and sensors in other locations.

\begin{tabular}{|l|l|}
\hline Aircraft type & Boeing 757-200 \\
\hline Engines & Two Rolls-Royce RB211 \\
\hline Maximum thrust & $43,100 \mathrm{Lb}$ \\
\hline Wing Span & $124 \mathrm{ft} 10 \mathrm{in}$ \\
\hline Height & $44 \mathrm{ft} 6 \mathrm{in}$ \\
\hline Length & $155 \mathrm{ft} 3 \mathrm{in}$ \\
\hline Maximum take-off weight & $230,000 \mathrm{lb}$ \\
\hline Maximum operating altitude & $42,000 \mathrm{ft}$ \\
\hline Maximum speed & $350 \mathrm{kts}$ (Mach 0.86 \\
\hline Acceleration force limits & $2.5 \mathrm{~g}$ to $-1.0 \mathrm{~g}$ \\
\hline
\end{tabular}

Table 4 NASA Langley Research Center ARIES dimension and performance characteristics 


\section{Flight Test Results}

There were 13 flight tests of the remote data acquisition unit and the command and control unit on the NASA Langley ARIES. Four test flights were completed in August 2001. Nine additional tests were performed from March -May 2002. During all tests, a single RDAU was mounted on the left main landing gear as shown in Fig 12. The command and control unit was mounted in a research pallet of the NASA Langley Research Center (LaRC) Boeing 757-200 Airborne Research Integrated Experiments System (ARIES). The flight test objectives were to validate the following: the wireless communication capabilities of the system, the hardware design, command and control; software operation; and, data acquisition, storage and retrieval. A very rigorous test of the mechanical design was achieved by mounting the device on the landing gear. The sensors listed in Table 1 were used to measure and record acoustic and dynamic response in proximity to main landing gear. During the initial flight tests, none of the autonomous features had been installed. The system was functioning as a remotely controlled data acquisition device.

The four flight tests of 2001 validated the mechanical design and software design. Examination of data files verified that all commands transmitted from the CCU were received by the RDAU. However, when the RDAU was commanded to return a status code or data, the communication was not consistent. Signals from the CCU to the RDAU were sent by an encoder connected to the parallel port. This encoder takes four bits from the parallel port and encodes them into a special signal that can be transmitted by the transceiver. This encoded signal was repeated several times during the transmission to ensure it gets through. The RDAU has a decoder that is matched to the CCU transceiver encoder. However, data and status signals from the RDAU were sent back as a standard RS-232 signal from the main RDAU computer. This signal was in the form of a packet that was recognized by the software in the CCU. A status reply was sent as one packet. The low power transceiver required extremely good ambient radio frequency conditions for the RDAU signals to be received by the CCU. Incomplete packets were not recognized by the computer. The best conditions for reliable RDAU transmission and CCU reception occurred when the gear was down and the runway (or taxiway) area beneath the wheels were not covered with rubber tire marks. Condition such as when the gear was retracted in the wheel well resulted in numerous loss receptions.

Thee encoder/decoder pairs were designed to be used in remote control applications. To improve reception of signals coming from the RDAU, an encoder was added to the RDAU computer parallel port and a decoder was added to the CCU transceiver interface box. This encoded signal contained information on file storage and measurement acquisition mode. The redesigned health monitoring architecture now has two methods to query the RDAU: the original RS 232 signal and the additional encoder/decoder pair. The modified architecture now has one encoder/decoder pair for sending CCU commands and another encoder/decoder pair for sending RDAU status and data.

The nine flights in 2002 were used to evaluate the modifications that were made after the first series of flights. All modifications greatly enhanced the performance of the system. The 4-bit encoder resulted in better communication connectivity between the RDAU and CCU. Flight test engineers were able to determine the recording status of the RDAU more reliably. For example, the flight test engineers could easily determine whether the RDAU was armed, triggered, or whether data had been collected. Other modifications between flight series were to mount sensors on RDAU casing and to have multiple files for storing measurements.

Measurements acquired during flights included take-offs; landings; vibration while gear was fully retracted; taxiing; and, touch and go landings. A measurement of a touch and go landing is shown in Fig 13. The measurement is taken from the accelerometer parallel to the velocity of the aircraft. The landing event was approximately $15 \mathrm{~s}$ in duration. The objective of the measurements was not to analyze the measured data but to validate the means to acquire the measurement. Fig 13 demonstrates that the remotely controlled data acquisition capability works. 


\section{Future Work}

Key attributes of the system have been demonstrated during flight tests on the NASA ARIES. The next phase of development is to apply expert systems that have been also developed at NASA Langley Research Center. The expert systems use parameterized fuzzy logic algorithms that allow the input-output mapping to be tuned. The expert systems will be installed to provide a means for performing autonomous analysis. A brief description of the expert systems is given in the next section.

Other future work is to use Linux operating systems at all operational levels of the architecture. The final goal is to install RDAUs throughout the aircraft and perform flight tests to demonstrate all operational levels including the terminal collection unit currently under development. All amplitude shift keying modulation transceivers will be replaced with frequency modulated transceiver with variable power control $(1-10 \mathrm{~mW})$. A frequency modulation transceiver is less susceptible to noise. Secured wireless cell phone chips are another possible communication option. The terminal collection unit is being developed as discussed in an earlier section.

Future development goals of the remote data acquisition unit include lower power consumption. The hardware casing is to have a smaller volume and area footprint. Sensors will be external to the housing and placed on flex circuits. The unit will have a wireless laptop/desktop PC control, communication and collection interface. The unit will have the ability to use vehicle power. New versions of the digital interface will have the processing capability of the on-board computer currently being used. The dual functionality of the digital interface will make it possible to eliminate the on-board computer. The digital interface requires less power consumption thereby requiring fewer batteries. The volume and area footprint of the RDAU will greatly be reduced because the RDAU computer is removed (less area) from the circuit board and fewer batteries are required (less volume). Many of the operational features of the RDAU will be transitioned into a system-on-chip based design. System-On-Chip (SoC) incorporates the processor and most of the peripherals and interfaces onto one chip. Benefits of SoC include reduced physical properties (mass, dimensions, power), reduced PCB layout, flexible external interface capability, and ease of software/hardware integration, and reduced development through software/hardware co-design methods allowed by such a design. This type of design can be implemented using available FPGA, CPLD, and highly-integrated micro-controller offerings from various companies.

The future design changes to the command and control unit are to make the unit portable and selfcontained. The unit is to be placed within a small volume ruggedized chassis which should make the unit easy to carry. The transceiver circuitry shall be placed within the chassis. The will also be a keypad interface and liquid crystal display. The CCU will use external power source but have Lithium batteries as a power back-up. SoC design will also be incorporated into future CCU designs to make the architecture attractive to small privately owned aircraft and other smaller vehicle. 


\section{Expert System Overview}

Expert systems will be implemented in all operational levels of the health monitoring architecture to facilitate autonomous analysis. They will also provide decision logic for the CCU (e.g., for regulating RDAUs). The expert systems will be developed from tuned fuzzy mapping algorithms. The expert systems will allow subjective reasoning to be applied to all results (or measurements) in addition to quantitative analysis. When pattern recognition is required for the expert systems, neural networks can be used. Fuzzy logic mapping algorithms and neural networks are used because they are computationally efficient. Ref 4 provides a detailed description of the development of the fuzzy expert system that is similar to what is to be implemented in this health-monitoring architecture. Fuzzy logic is used to emulate predicate reasoning (i.e., if " $\mathrm{A}$ " then "B") for many combinations of inputs which are used to form a decision. Fuzzy logic can also emulate human qualitative reasoning with the capability of incorporating multiple qualitative objectives. Conceptually, a fuzzy expert system is similar to that of a decision-logic architecture using a collection of binary "if-then" rules. The advantage of using fuzzy logic expert systems is that they can interpolate or extrapolate with fewer rules than the traditional binary expert systems. Fuzzy expert systems are robust. They have been shown to produce very good results in cases where the mathematical description of the system being controlled or analyzed may not be readily available; the description may be of questionable fidelity; or, the inputs are imprecise.

A fuzzy expert system development algorithm has been developed at NASA Langley Research Center that will allow users to develop a fuzzy expert system without having to be knowledgeable in fuzzy logic. The development algorithm is optimization based. The development algorithm only requires that a user defines his/hers subjective reasoning into a set of decision rules of the form, "If A and If B ... then C." The user also supplies examples of metrics for those rules. The rules form a rule matrix. Nested in the expert system development algorithm is a fuzzy mapping algorithm that dynamically sizes its working matrices to accommodate the user-supplied rules. The mapping algorithm is capable of determining permutations of all rules executed based upon current inputs. The development algorithm uses the rule matrix to develop an optimization design vector based upon the number of fuzzy membership sets in the rules. The usersupplied metrics are used to tune the expert system via an optimization strategy. The optimization design objective is to minimize the error between the user supplied output metrics and the outputs the mapping algorithm creates for the same set of inputs. The design vector is varied using methods such as gradient or genetic algorithms. The fuzzy expert system is tuned when a design vector is developed such that when implemented in the fuzzy mapping algorithm, the mapping algorithm's output approximates those of the user for a given set of inputs. Before the development algorithm, making a fuzzy expert system required the user to formulate membership functions for various fuzzy sets; develop rules that map input conditions to decisions using fuzzy sets; and, select fuzzification and defuzzification techniques for a small number of options.

The remote data acquisition unit expert system will be trained using measurements collected when the vehicle is operating according to design are used to establish a baseline. The user defines the significance (e.g., how bad does the measurement indicate the vehicle is?) of new measurements that are acquired which are not within established envelopes of the baselines. This gives the architecture the ability to autonomously analyze measurements to ascertain the health of the vehicle. The expert systems for the command and control unit and the terminal collection unit will be developed in a similar fashion. 


\section{Conclusions}

On-going development and testing of an adaptable vehicle health-monitoring architecture has been presented. The objective of the health monitoring architecture is to reduce vehicle operating costs, improve safety and increase reliability. The architecture is being developed such that it can be retrofitted into a fleet of vehicles. There are three operational levels to the architecture: one or more remote data acquisition units located throughout the vehicle; a command and control unit located within the vehicle; and, a terminal collection unit to collect analysis results from all vehicles.

Fuzzy expert systems will be implemented in all operational levels. The expert systems are developed such that they can be trained for any vehicle or structure to perform autonomous analysis. The expert systems are parameterized to allow them to be adapted to a given suite of sensors. Expert systems provide a means to include an user's subjective reasoning and quantitative methods into autonomous analyses. Once a suite of sensors are chosen for each RDAU and located on the vehicle, a baseline of acceptable vehicle performance is established from measurements acquired when the vehicle is performing correctly. The RDAU embedded expert system can then be trained to its respective baseline.

The architecture provides an infrastructure for performing tributary analyses. The measurements collected at the lowest level are analyzed at that level. Analysis results are forwarded to next operational level and then all results are analyzed to ascertain global trends or anomalies for the prior level. This is repeated until all analyses are combined at the highest level. The advantage of the having expert systems at each analysis level is that it can eliminate the need for transmitting and storing large volumes of collected measurements. Forwarding only analysis results to the next operational level reduces telemetry congestion.

The remote data acquisition unit has an eight channel programmable digital interface which allows the user discretion for choosing type of sensors; number of sensors, sensor sampling rate and sampling duration for each sensor. The parameterized trainable fuzzy expert system and the programmable digital interface make health monitoring hardware and software infrastructure adaptable to many vehicles and structures.

All communication within the architecture is done with wireless transceivers operated at $433 \mathrm{MHz}$ and $1 \mathrm{~mW}$. Electromagnetic interference tests have demonstrated that the radio frequency emissions from the transceivers have no influence on any of the aircraft communication and navigation antennae. The remote data acquisition unit has been thermally tested for temperatures ranging from $-50^{\circ} \mathrm{C}$ to $55^{\circ} \mathrm{C}$. Pressure testing verified that the RDAU could be used in non-environmentally controlled spaces on an aircraft at $50,000 \mathrm{ft}$ altitude. Vibration tests verified that the remote data acquisition unit could operate during vibration representative of that which commercial aircraft experience. During vibration testing, the final acceleration amplitude was $20 \mathrm{~g}$ at $2000 \mathrm{~Hz}$.

Potential hazards were identified and analyzed to assure safety during the test flights. Extensive airworthiness and safety reviews of the remote data acquisition unit design and the preflight testing was used to alleviate the potential hazards identified. Installment of all health monitoring subsystems was given thorough flight quality assurance inspections.

There were 13 flight tests of the remote data acquisition unit and the command and control unit on the NASA Langley Airborne Research Integrated Experiments System (ARIES). The flight tests were performed to validate the following: the wireless radio frequency communication capabilities of the system, the hardware design, command and control; software operation; and, data acquisition, storage and retrieval. A very rigorous test of the mechanical design was achieved by mounting the device on the left main landing gear. During the initial flight tests, none of the autonomous features had been installed. The system functioned as a remotely controlled data acquisition device.

Four test flights were completed in August 2001. The four flight tests of 2001 validated the mechanical design and software design. The tests indicated that radio frequency communications needed to be modified to be more reliable. Another 4-bit encoder/decoder pair was added to the system. Multiple data storage files were added. The nine flights in March - May 2002 were used to evaluate the modifications that were made after the first series of flights. All modifications greatly enhanced the performance of the 
system. The final series of flight tests demonstrated that the remotely controlled data acquisition capability worked correctly. 


\section{Acknowledgements}

The authors would like to thank the following individuals at NASA Langley Research Center for their support: G. H. Wheatle, K. C. Powell, D. J. Jones R. H. Daugherty, E. L. Kirby, B. D. Fisher, Dr. W. H. Prosser, R. C. Webster, F. D. Fitzpatrick, H. C. Jones, J. L. Pierro, L. H. Crittenden and M. S. Wusk.

\section{References}

1. RTCA, Inc., July 29, 1997, RTCA/DO-160D, Environmental Conditions and Test Procedures for Airborne Equipment, Washington, DC, RTCA, Inc.

2. Rollins, C. H., "Electromagnetic Compatibility Testing For The NASA Langley Research Center Boeing 757-200" The "20th Digital Avionics Systems Conference" Daytona Beach, FL Oct 14 -18, 2001. Presented in the Flight Critical Systems-Electromagnetic Effects II session, Paper No. 36

3. NASA FS-1999-12-41-LaRC, December 1999, “ARIES: NASA's 'Flying Lab’ Takes Wing”

4. Woodard, S. E. and Pappa, R. S. "Development of Structural Identification Accuracy Indicators Using Fuzzy Logic," Proceedings of the 1997 ASME Design Engineering Technical Conferences, ASME DETC97/VIB-4258, Sacramento, CA, September 14-17, 1997 


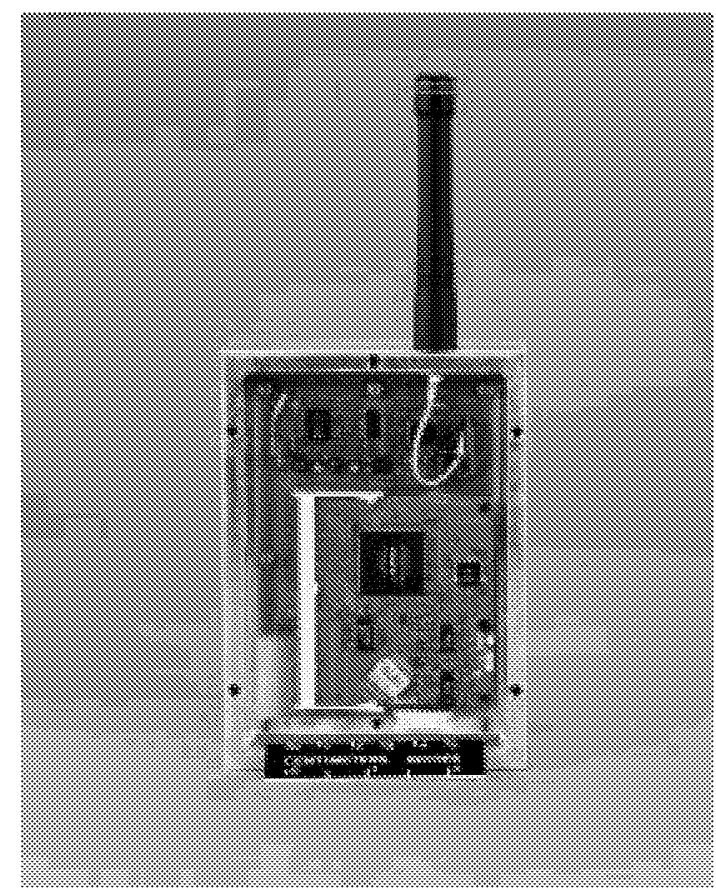

a. Remote data acquisition unit electronics

Fig 1. Remote data acquistion unit (RDUA)

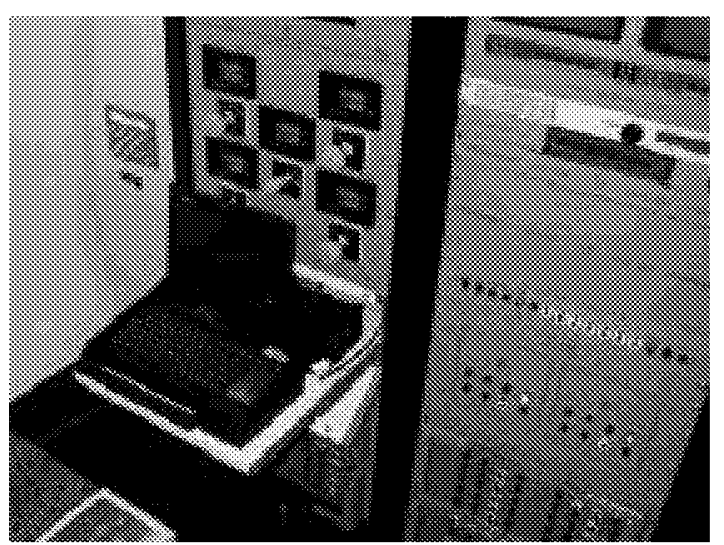

a. Command and control unit mounted on NASA Langley Boeing 757 experiment pallet

Fig. 2 Command and control unit

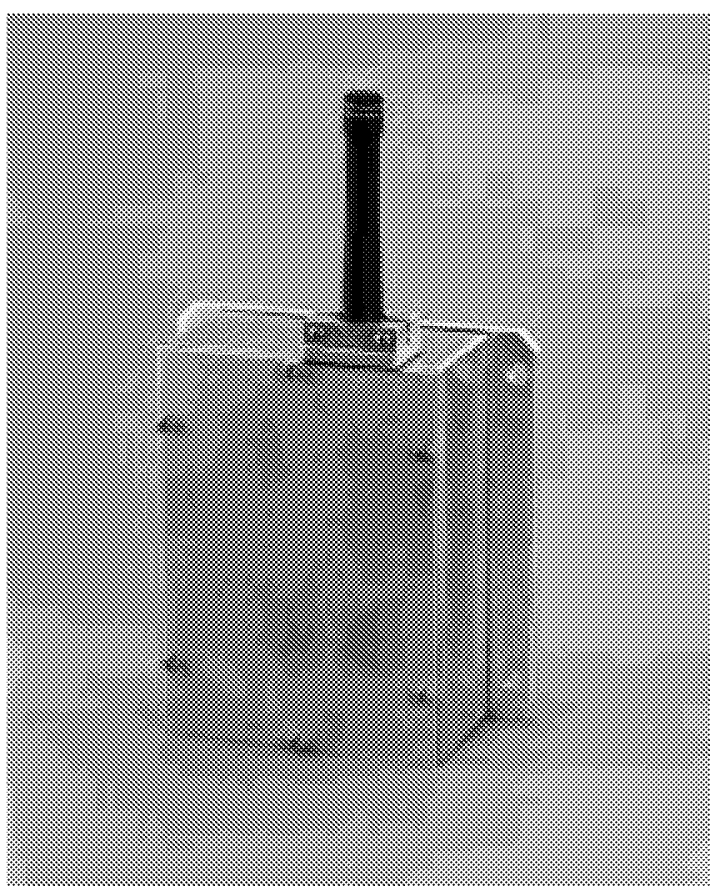

b. Remote data acquisition unit housing

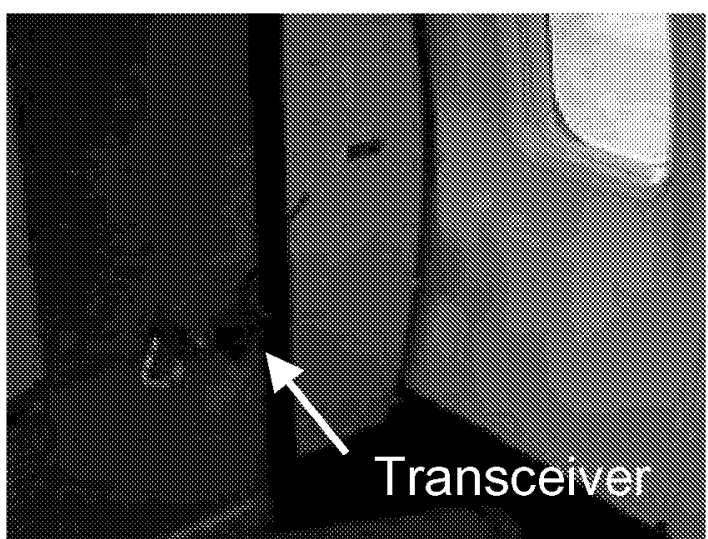

b. Command and control unit transceiver mounted at rear of experiment pallet 


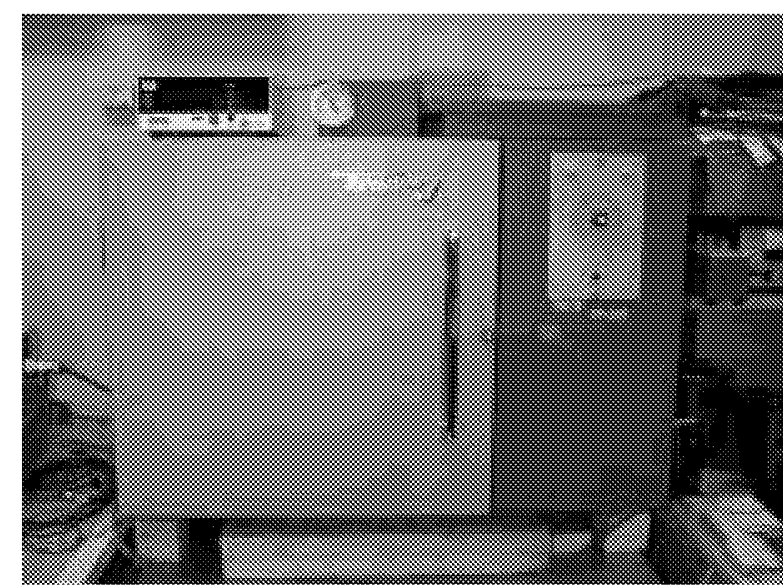

a. Temperature chamber

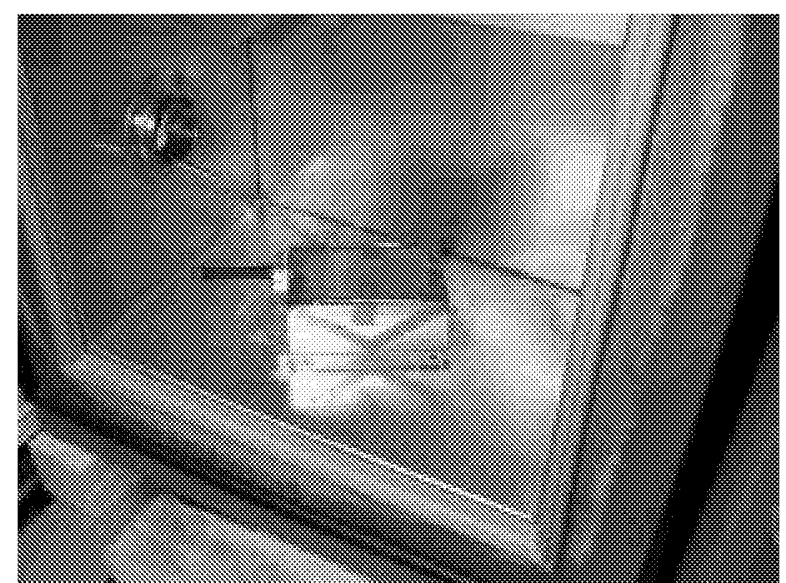

b. RDAU inside chamber before testing

Fig. 3 Tenney Jr. Temperature Chamber used for testing RDAU operation during thermal cycling

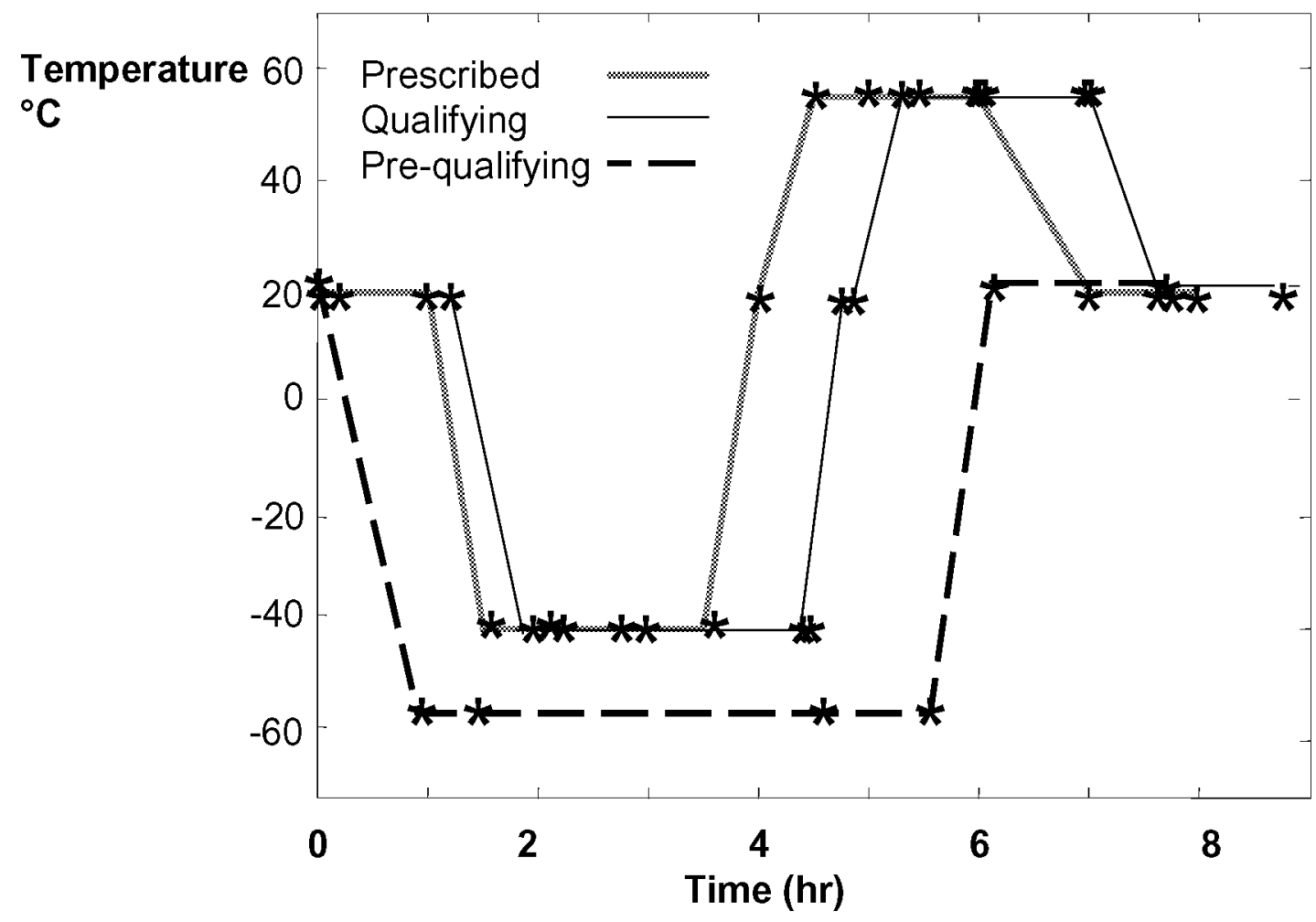

Fig 4 Temperature profile used for thermal cycling remote data acquisition unit. Measurement occurred during the times annotated with the asterisk. 


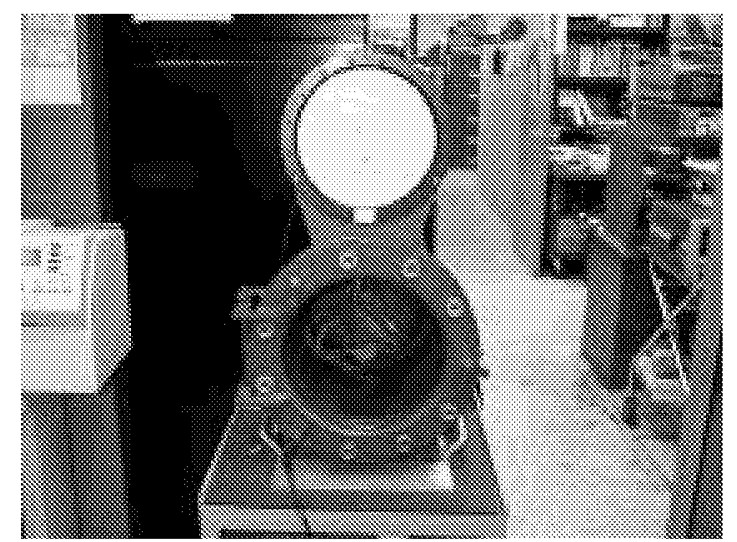

a. Process Equipment Co. Vacuum Chamber

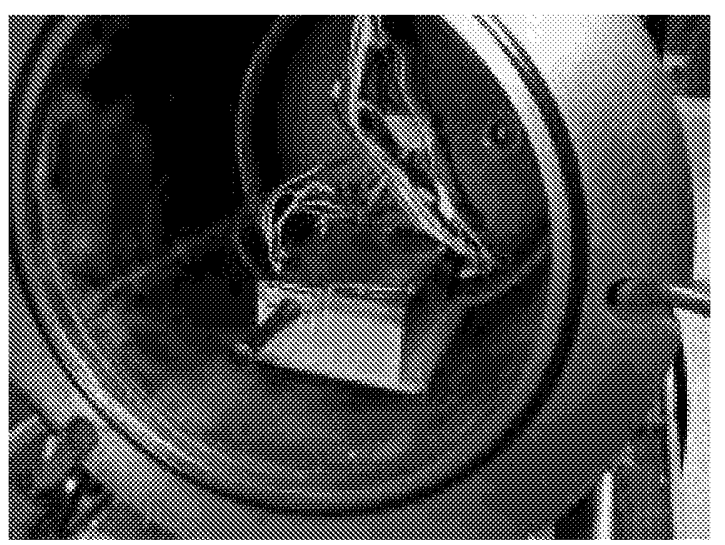

b. RDAU inside chamber before testing

Fig. 5 Process Equipment Co. Vacuum Chamber used for testing RDAU operation at pressure emulating $50,000 \mathrm{ft}$

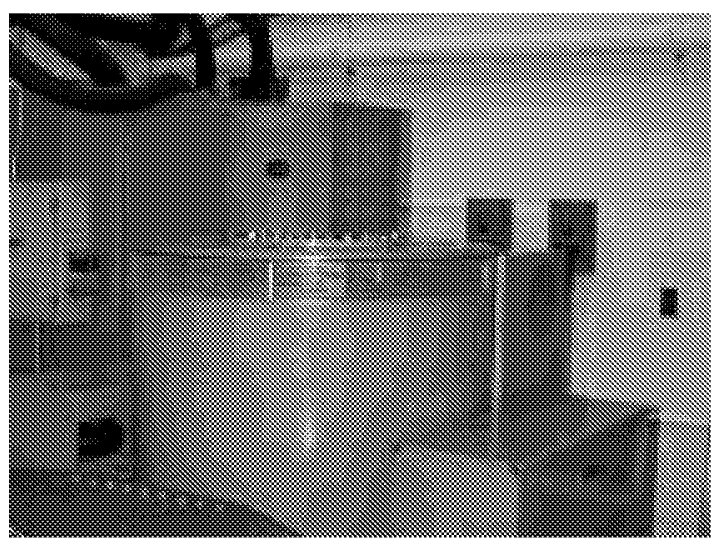

a. T1000Unholtz-Dickie vibration table.

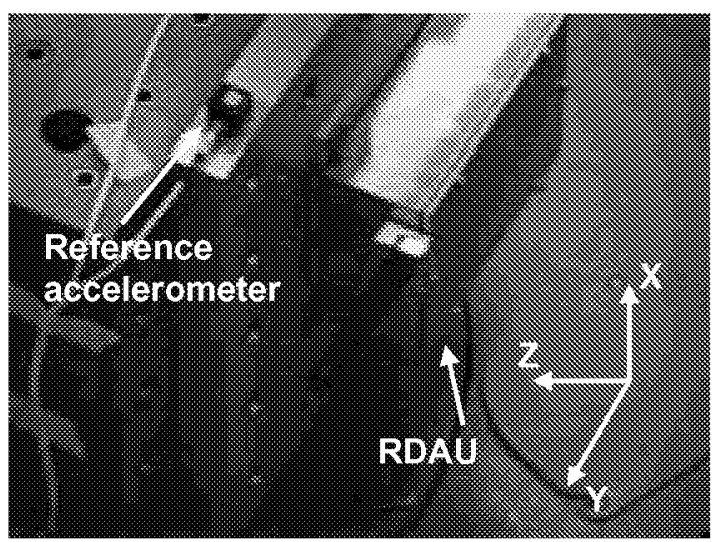

b. Axis orientation of RDAU during vibration testing.

Fig 6. Vibration table and RDAU during vibration testing. 


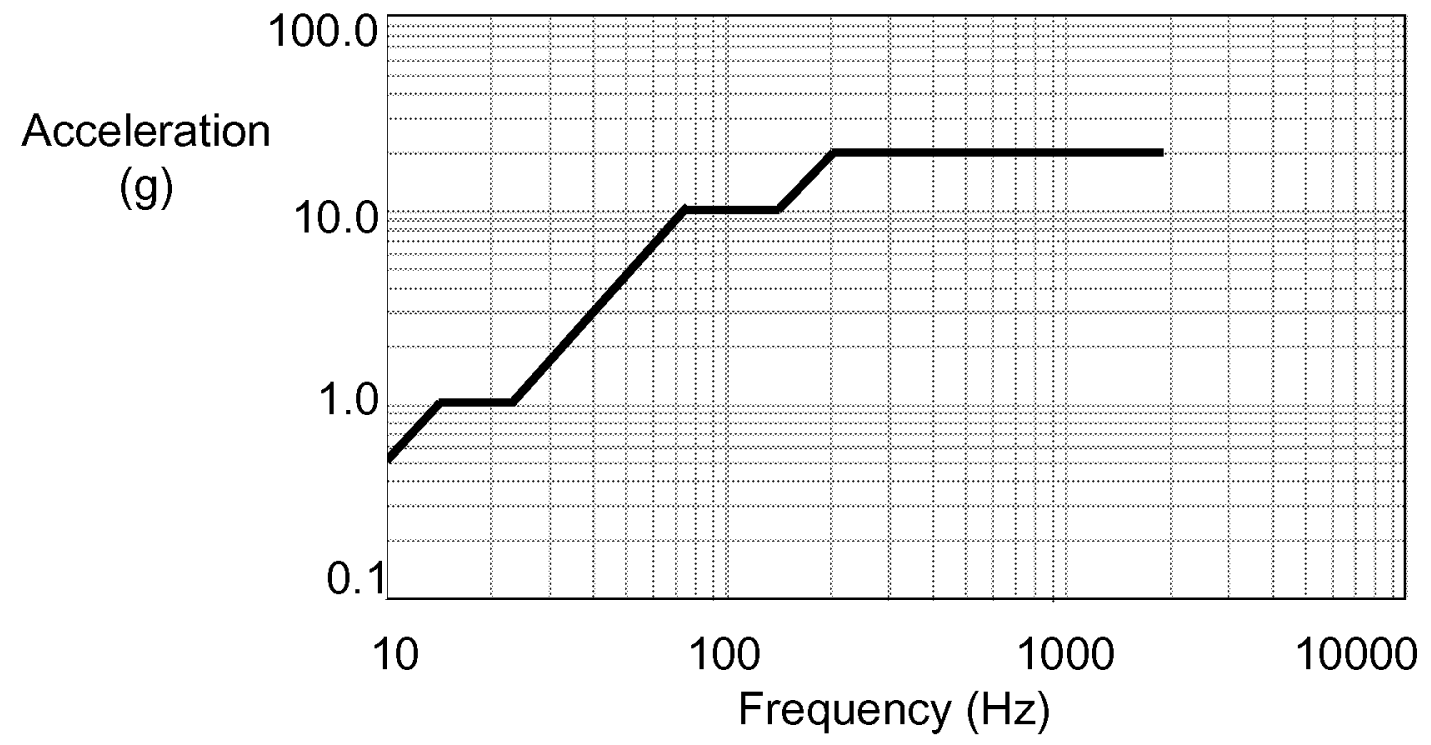

Fig 7 Standard acceleration profile used during vibration testing for each axis.

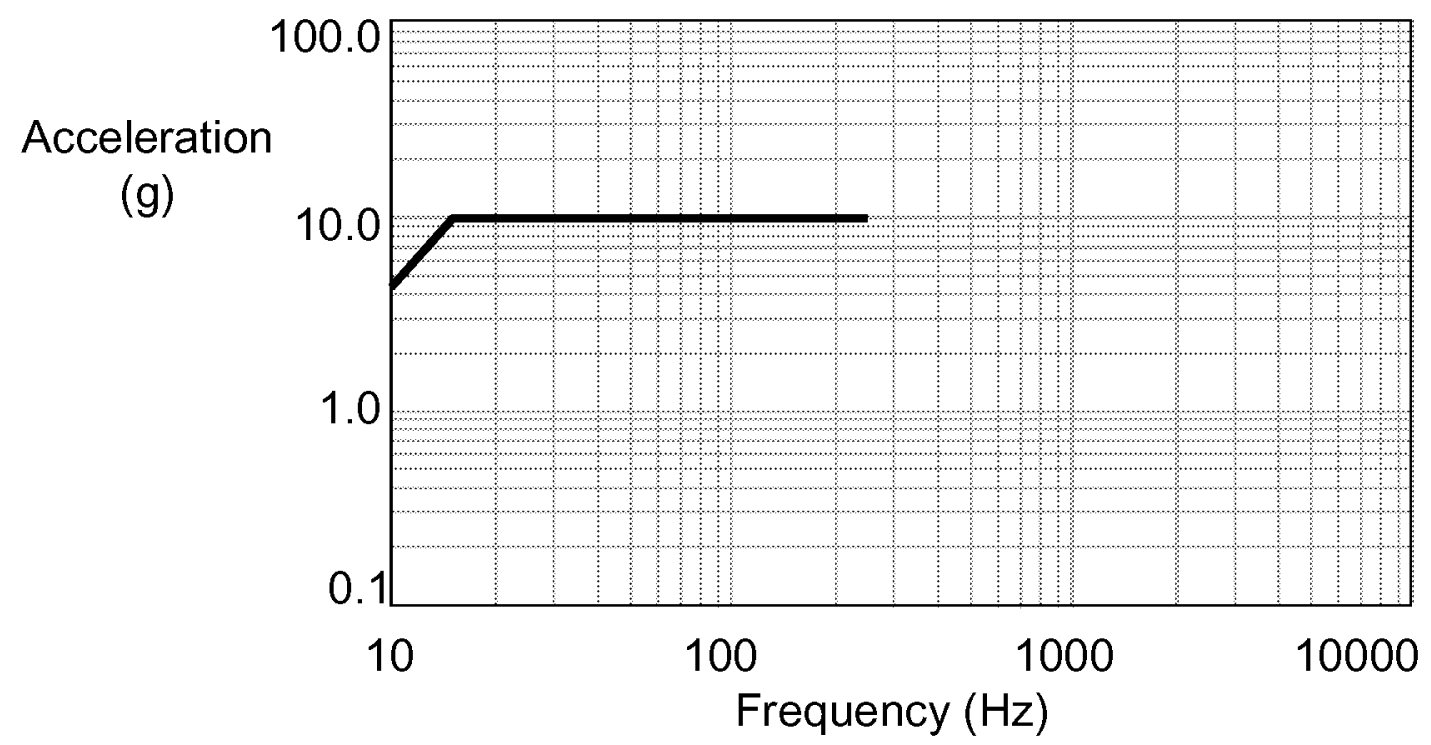

Fig 8 Acceleration profile during vibration testing used for each axis. 


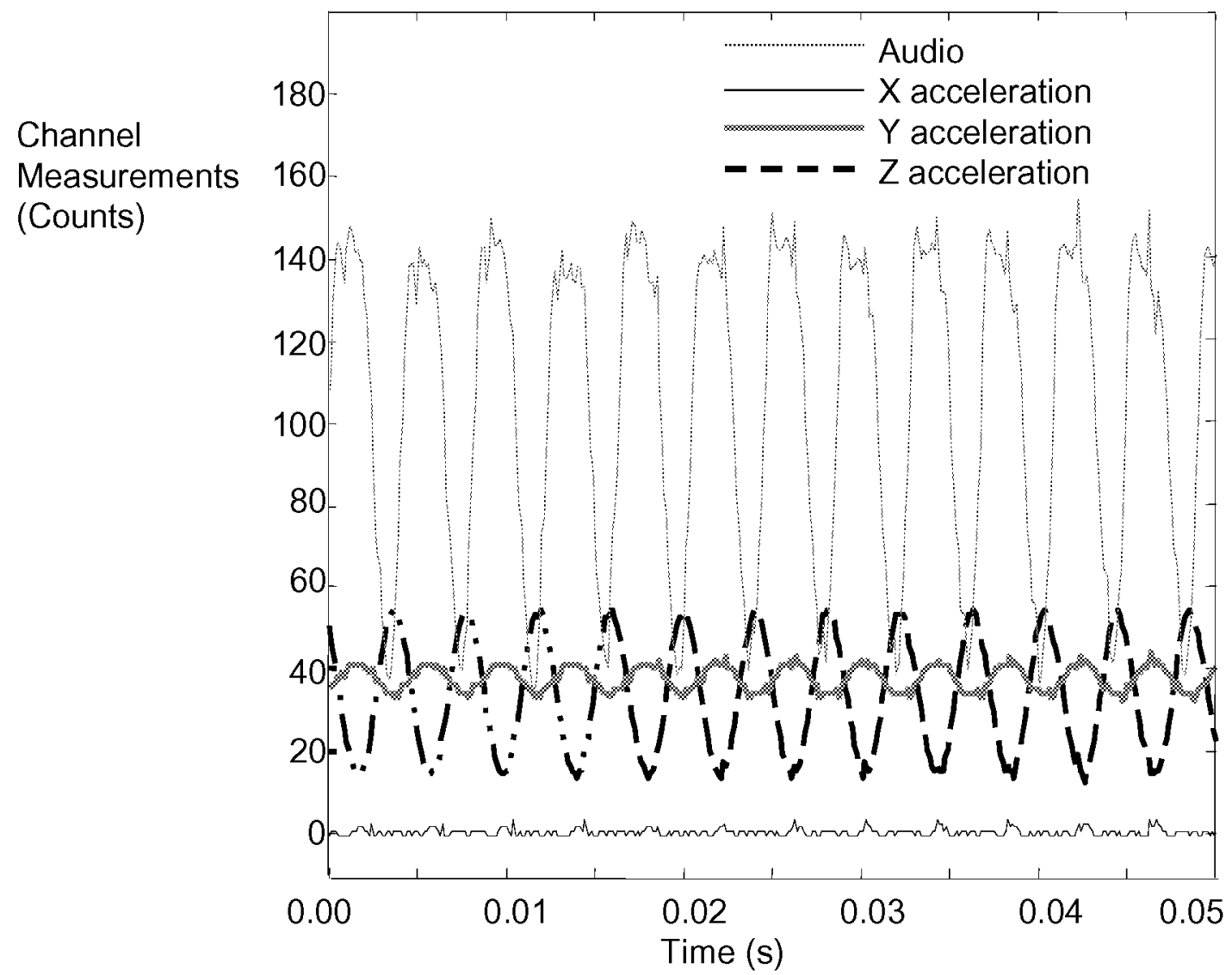

Fig 9 Vibration response measured using RDAU during vibration test compare to accelerometers mounted on vibration table. 


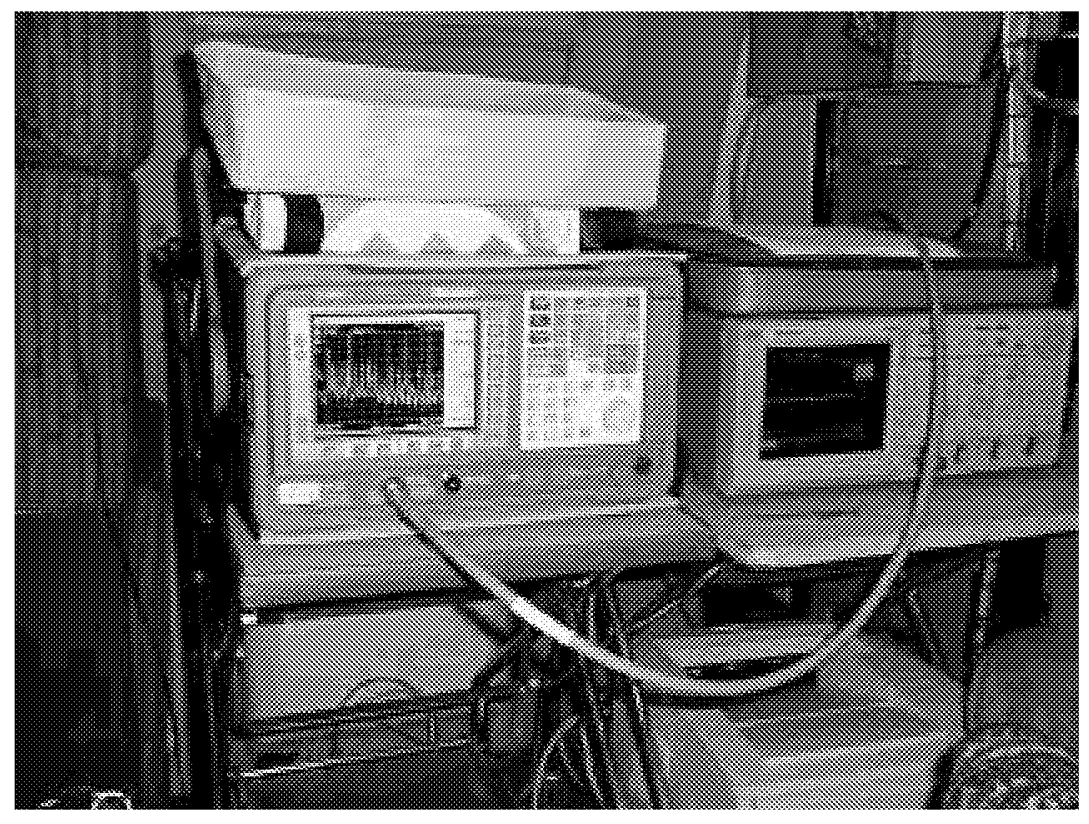

Fig 10 Frequency analyzer with signal input from an electromagnetic interference receiver. 


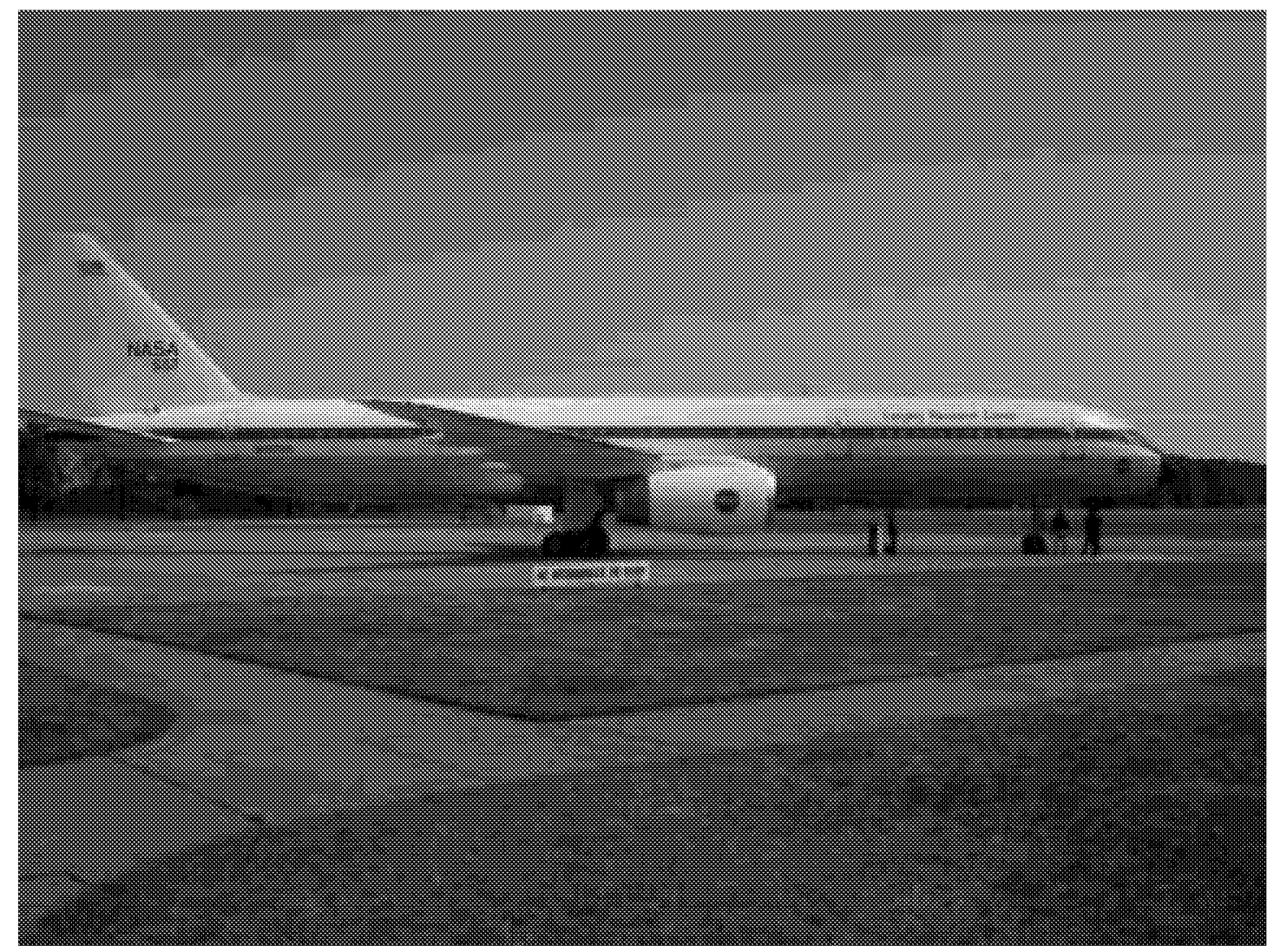

Fig 11 Langley Research Center (LaRC) Boeing 757-200 aircraft: Airborne Research Integrated Experiments System (ARIES). 


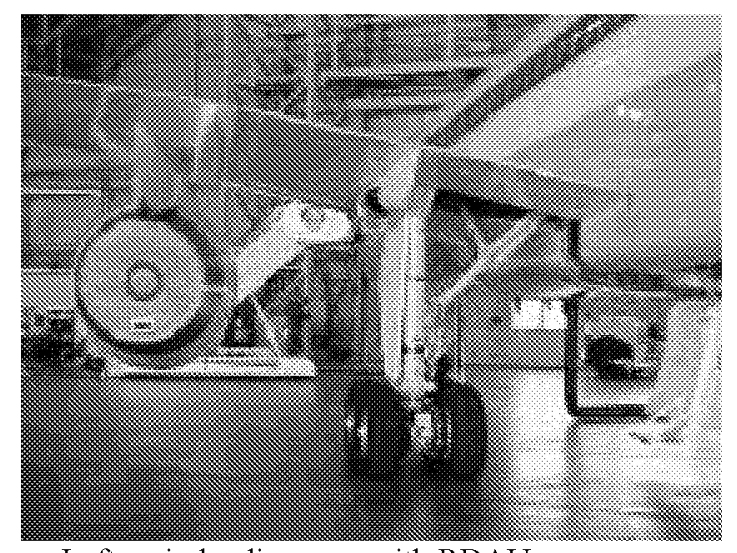

a. Left main landing gear with RDAU

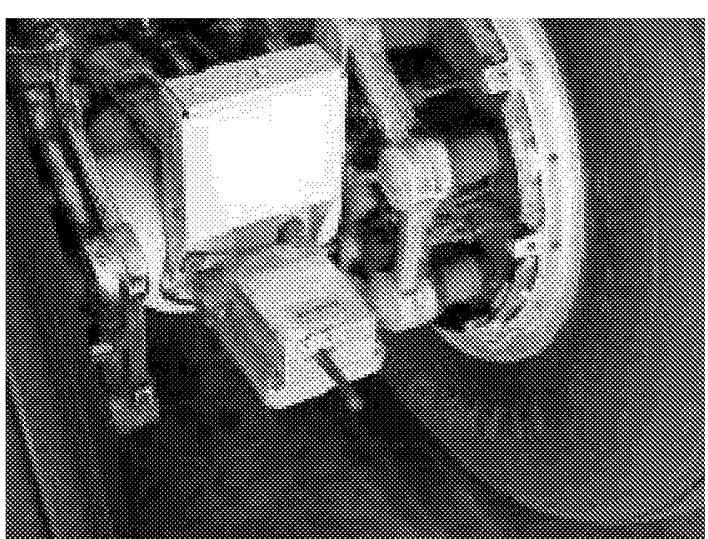

b. RDAU mounted on tow fitting of landing gear

Fig. 12 Remote Data Acquistion Unit (RDUA) mounted on NASA Langley Boeing 757 main landing gear.

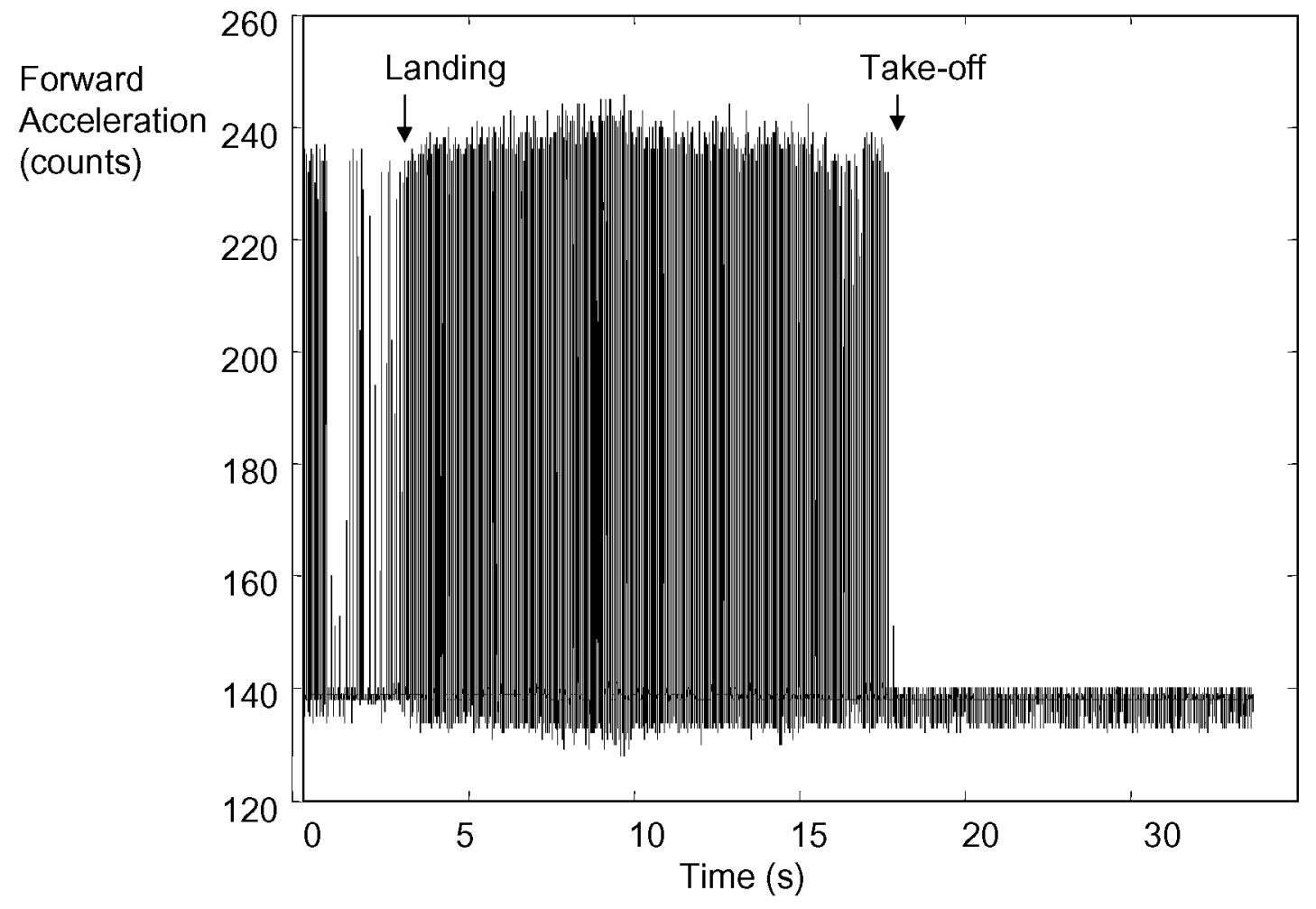

Fig. 13 Forward acceleration measured by RDAU during touch and go landing at Langley Air Force Base (April 24, 2002) 


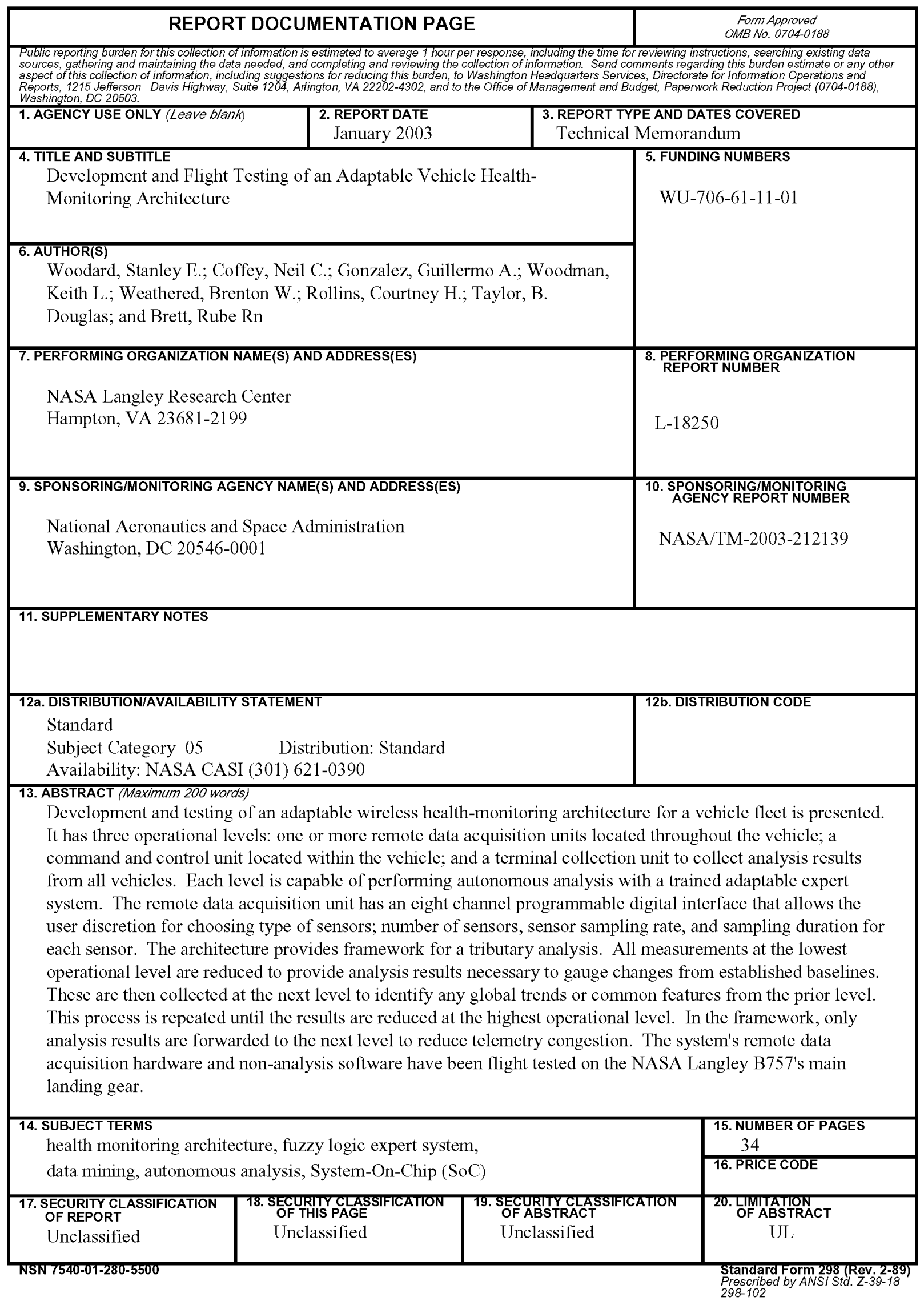

